\title{
Shoulder dystocia among parous parturients: Birth weight differences of the largest prior vaginal delivery and index
} pregnancy

\author{
Suneet P. Chauhan ${ }^{1}$, Kenny Choi ${ }^{2}$, Everett F. Magann ${ }^{2}$, Sharon D. Keiser ${ }^{3}$, Jonathan F. Rehberg ${ }^{4}$ and John C. Morrison ${ }^{* 4}$ \\ ${ }^{1}$ Departments of Obstetrics and Gynecology, Houston, Texas, USA \\ ${ }^{2}$ University of Arkansas for Medical Sciences, Little Rock, AR, USA \\ ${ }^{3}$ Spartanburg Regional Medical center, Spartanburg, South Carolina, USA \\ ${ }^{4}$ University of Mississippi Medical Center, Jackson, Mississippi, USA
}

\begin{abstract}
To compare the birth weight (BW) of largest prior vaginal delivery versus the index pregnancy with shoulder dystocia (SD). From three centers, births with SD were identified and compared to the largest birth weight of prior delivery at term. Among 304 patients, the mean difference in the BW of those with SD in the index pregnancy and largest prior vaginal delivery was $394 \pm 510 \mathrm{~g}$ ( $\mathrm{p}<.0001)$. The mean differences in BW of those with dystocia and subsequent brachial plexus injury (BPI; $614 \pm 569 \mathrm{~g})$ versus those without BPI $(384.1 \pm 508.3 \mathrm{~g})$ were also significantly different $(\mathrm{p}=0.016)$. There are significant birth weight differences between current and prior birth weight as a predictor of shoulder dystocia with/without BPI. Unfortunately, these findings cannot be used clinically because of the inaccuracy of estimating birth weight.
\end{abstract}

\section{Introduction}

Shoulder dystocia (SD) is defined as difficulty with delivery, marked by a shoulder-head interval of $>1$ min or as need for ancillary maneuvers to free the shoulder and occurs in $0.2-3 \%$ of vaginal births [1]. Since it can be associated with temporary or permanent injury to brachial plexus (BPI), and allegations of medical liability vs. maloccurence, it is understandable why there is need to differentiate which pregnancy is at risk for an impacted shoulder [2-4]. The cause of shoulder dystocia and subsequent BPI has erroneously been assumed in the past to occur only following excessive lateral traction on the baby's head by the accoucheur [4]. However, it is now accepted that BPI, with or without shoulder dystocia, is associated with in utero causes such as, excessive pressure on the anterior/posterior shoulder over time and/or excessive twisting as the fetus passes through the pelvis often during precipitate deliveries [5]. Other, more rare, intrauterine causes BPI include; congenital malformations, fetal drug exposure, viral infections, and uterine malformations [6].

Retrospective studies have identified risk factors for shoulder dystocia, but such risk factors have such a low positive predictive value $(<18 \%)$ they are not useful clinically in a index pregnancy [7]. Since macrosomia is more often associated with shoulder dystocia an awareness of newborns birth weight delivered previously might be predictive of recurrence. Certainly as a negative predictor, birth weight has proved helpful such as when a pelvis has been proven for a specific weight it is usually noted that the next pregnancy of a similar or lesser birth weight is not problematic [4]. Similarly, a patient who has delivered a macrocosmic newborn without difficulty, it is usually found that subsequent fetuses of a similar weight will delivery without difficulty. There is, however, no previous report on parous patients and the differences in birth weight between the previous and current newborn when the latter is complicated by shoulder dystocia.

The purpose of this retrospective, multi-center study was to describe a cohort of parous parturients with shoulder dystocia is the index pregnancy versus the heaviest birth weight of prior newborn without dystocia or BPI, and to contrast parous parturients with a shoulder dystocia in the current gestation who had delivered a fetus $\geq 4,000$ g compared to those who had not.

\section{Materials and methods}

Over a five year, in three tertiary centers, ICD-9 codes were used to document all parous patients who had shoulder dystocia with or without BPI. In addition, labor/delivery and operating room scheduling books were interrogated to insure that no patient with this diagnosis had been omitted. Finally, newborn records from the same time period were scanned to insure diagnostic accuracy to detect BPI following shoulder dystocia. From the records at each center we investigated the birth weight and obstetric history of the prior vaginal birth, as well as the index newborns' weight, which was complicated by shoulder dystocia. Additionally, we obtained the antepartum and intrapartum characteristics of the index pregnancy, the maneuvers used to resolve shoulder dystocia and whether the index newborn sustained any injury.

The inclusion criteria for this study using our database were women

Correspondence to: John C. Morrison, M.D, Department of Obstetrics and Gynecology, University of Mississippi Medical Center, 2500 North State Street, Jackson, MS 39216-4505, USA, E-mail: jmorrison@umc.edu

Received: April 15, 2015; Accepted: May 04, 2015; Published: May 06, 2015 
with prior vaginal delivery at term, know birth weight of prior siblings and shoulder dystocia with the index (current) pregnancy. Twin pregnancy and cesarean section delivery without at least one vaginal term birth were excluded as were anomalous fetuses. The study was approved by Institutional Review Board at two centers and exempted from another.

Along with odds ratio (OR) and $95 \%$ confidence intervals (CI), Mann-Whitney or unpaired t-test were used where appropriate. $\mathrm{P}<0.05$ and CI not crossing integer 1 were considered significant.

\section{Results}

Over a five year period there were $624 \mathrm{SD}$ in the database, and 304 (49\%) met the inclusion criteria and are the focus of the study. Only $3 \%(10 / 304)$ of the cohort had prior SD and none of them had a newborn with brachial plexus injury (BPI). The mean difference in the prior largest and the current BW with SD was $394 \pm 510 \mathrm{~g}$ heavier. In the index pregnancy, $10 \%$ had instrument assisted vaginal birth, $7 \%$ $(20 / 304)$ BPI, and 3\% (10/304) a fracture of the clavicle or humerus (Table 1).

As noted on Table 1, 79\% (241/304) of the cohort, the index pregnancy with SD was the heaviest newborn for parturient (Group I) and with $21 \%(63 / 304)$, a previous newborn delivered vaginally weighted more than current one (Group II). These two groups were similar with regard to diabetes, use of epidural anesthesia, whether or not they were induced/augmented and rate of spontaneous birth versus delivery with vacuum/forceps (Table 1). Paradoxically, the rate of recurrent shoulder dystocia was significantly lower in Group I than II ( $2 \%$ vs $10 \%$; OR $0.16,95 \%$ CI $0.04,0.59$ ). The two groups did not differ significantly regarding the mean number of maneuvers and whether $\geq 3$ were used to relieve SD, the rate of BPI or fracture of clavicle/humerus.

Previously, 17\% (54/301) of the cohort had delivered a macrosomic fetus vaginally and yet $30 \%(16 / 54)$ had SD with neonates that weighed $<4,000 \mathrm{~g}$ in the index case (Table 2). Maternal age was greater in those with prior macrosomic babies and they had a higher rate of shoulder dystocia (7vs 3, OR 12.58, CI 3.14, 50.45). The rate of diabetes, induced/ augmented pregnancies, epidurals, instrumented deliveries, the number of maneuvers and whether or not BPI was present was not different between the two groups. As one would expect, the comparison in prior largest birth weight and the difference between the two was statistically significant (Table 2).

Backward stepwise logistic regression indentified that the five significant risk factors for BPI among parous parturients: 1) African American race (as compared to Caucasian) (OR 4.69; 95\% CI 1.2517.56); 2) use of epidural anesthesia (OR 6.95; 95\% CI 1.66-29.07); 3) use of suprapubic pressure, (OR 6.42; 95\% CI 1.33-31.0); 4) extraction of the posterior arm (OR 9.30; 95\% CI 2.07-41.82) and 5) birth weight difference between the previous largest newborn and index pregnancy of $725 \mathrm{~g}$ or more (OR $4.10,95 \%$ CI 1.41-11-91).

\section{Discussion}

There are three principal findings in our study. First, only $3 \%(10$ out of 304) had a prior shoulder dystocia among women who delivered a baby complicated by shoulder dystocia in the index pregnancy. None of the infants with a prior shoulder dystocia had brachial plexus injury whereas 7\% (20/304) had BPI and 3\% (10/304) had fracture of the clavicle or humerus in the index pregnancy. Surprisingly, there were no differences in prior largest birth weight between those who had shoulder dystocia plus BPI $(3496 \pm 483, \mathrm{p}=.704)$. Likewise, birth weight $>4000$ gm was also not significantly different amongst the group with BPI compared to the group of patients with shoulder dystocia without BPI $(p=.113)$. Between the two groups, the percent with a difference in birth weights of $>10 \%$ were higher when the heaviest baby was the prior delivery ( $\mathrm{p}=.024$, Table 1$)$. Accordingly, having had a prior

Table 1. Parous parturients with shoulder dystocia.

\begin{tabular}{|c|c|c|c|}
\hline & $\begin{array}{c}\text { Group I } \\
\text { Largest BW with } \\
\text { Index Pregnancy } \\
\quad(\mathrm{N}=241)\end{array}$ & $\begin{array}{c}\text { Group II } \\
\text { Prior Delivery } \\
\text { with Largest BW } \\
(\mathrm{N}=63)\end{array}$ & $\begin{array}{c}\mathrm{P} / \\
\text { Odds Ratio } \\
(95 \% \text { confidence intervals })\end{array}$ \\
\hline Age & $27.3 \pm 5.3$ & $29.5 \pm 1.2$ & $0.011^{\wedge}$ \\
\hline Gestational age (weeks) & $39.4 \pm 1.1$ & $39.1 \pm 1.2$ & $0.166^{\wedge}$ \\
\hline Prior Largest (BW grams`) & $3428 \pm 448$ & $3945 \pm 381$ & $<0.0001^{*}$ \\
\hline Prior shoulder dystocia & $2 \%(4)$ & $10 \%(6)$ & $0.16(0.04,0.59)$ \\
\hline Diabetes - gestational or pregestational & $7 \%(17)$ & $8 \%(5)$ & $0.88(0.31,2.49)$ \\
\hline Induced/Augmented & $68 \%(163)$ & $93 \%(42)$ & $1.04(0.58,188)$ \\
\hline Epidural & $62 \%(149)$ & $63 \%(40)$ & $0.93(0.36,2.32)$ \\
\hline Spontaneous vaginal delivery & $90 \%(216)$ & $90 \%(57)$ & $<0.0001^{*}$ \\
\hline Birth weight $(\mathrm{g})$ & $4013 \pm 428$ & $3635 \pm 395$ & $<0.0001^{\wedge}$ \\
\hline $\begin{array}{l}\text { Prior largest BW - } \\
\text { Current BW (g) }\end{array}$ & $333 \pm 617$ & $-273 \pm 310$ & $<0.0001^{\wedge}$ \\
\hline $\begin{array}{l}\text { Maneuvers } \\
\text { McRoberts } \\
\text { Suprapubic } \\
\text { Woods } \\
\text { Extraction of arm }\end{array}$ & $\begin{array}{c}1.7 \pm 0.8 \\
88 \%(213) \\
61 \%(148) \\
16 \%(38) \\
5 \%(13)\end{array}$ & $\begin{array}{l}1.5 \pm 0.7 \\
94 \%(59) \\
52 \%(33) \\
8 \%(5) \\
3 \%(2)\end{array}$ & $\begin{array}{c}0.215 \\
0.51(0.17,1.53) \\
1.44(0.82,2.53) \\
2.17(0.82,5.77) \\
1.74(0.38,7.92)\end{array}$ \\
\hline Three maneuvers or more & $13 \%(32)$ & $8 \%(5)$ & $1.78(0.66,4.76)$ \\
\hline Fracture - clavicle or humerus & $4 \%(9)$ & $2 \%(1)$ & $2.40(0.29,19.36)$ \\
\hline Brachial plexus injury & $7 \%(18)$ & $3 \%(2)$ & $2.46(0.56,19.91)$ \\
\hline
\end{tabular}

Data as mean \pm standard deviation or $\%(\mathrm{n}){ }^{\bullet} \mathrm{BW}=$ birth weight in grams

${ }^{\wedge}$ Mann-Whitney test used (failed normality test) *Unpaired t-test 
Table 2. Parous parturients with shoulder dystocia and prior vaginal delivery of macrosomic fetus.

\begin{tabular}{|c|c|c|c|}
\hline & $\begin{array}{c}\text { Prior } B W \geq 4,000 \mathrm{~g} \\
(N=53)\end{array}$ & $\begin{array}{c}\text { Prior } \mathrm{BW} \leq \mathbf{3 , 9 9 9} \mathrm{g} \\
(\mathrm{N}=\mathbf{2 5 1})\end{array}$ & $\begin{array}{c}\mathbf{P} / \\
\text { OR }(95 \% \mathrm{CI})^{\mathrm{x}}\end{array}$ \\
\hline Age & $30.1 \pm 6.2$ & $27.2 \pm 5.3$ & $0.002^{\wedge}$ \\
\hline Gestational age (weeks) & $39.4 \pm 1.1$ & $39.3 \pm 1.1$ & $0.880^{\wedge}$ \\
\hline Prior Largest (BW grams`) & $4222 \pm 206$ & $3390 \pm 388$ & $<0.0001^{\wedge}$ \\
\hline Prior shoulder dystocia & $13 \%(7)$ & $1 \%(3)$ & $12.58(3.14,50.45)$ \\
\hline Diabetes - gestational or pregestational & $6 \%(3)$ & $8 \%(19)$ & $0.88(0.31,2.49)$ \\
\hline Induced/Augmented & $66 \%(35)$ & $68 \%(170)$ & $0.93(0.49,1.73)$ \\
\hline Epidural & $68 \%(36)$ & $61 \%(153)$ & $1.36(0.72,2.54)$ \\
\hline Spontaneous vaginal delivery & $94 \%(50)$ & $89 \%(223)$ & $2.09(0.61,7.15)$ \\
\hline $\begin{array}{l}\text { Birth weight (g) } \\
\geq 4,000 \mathrm{~g}\end{array}$ & $\begin{array}{c}4179 \pm 511 \\
70 \%(37)\end{array}$ & $\begin{array}{c}3883 \pm 417 \\
38 \%(95)\end{array}$ & $\begin{array}{c}<0.0001 * \\
3.73(2.00,7.19)\end{array}$ \\
\hline $\begin{array}{l}\text { Prior largest BW - } \\
\text { Current BW (g) }\end{array}$ & $-66 \pm 493$ & $264 \pm 627$ & $<0.004^{*}$ \\
\hline$\%$ Difference & $-2.4 \pm 12.6 \%$ & $12.0 \pm 11.7 \%$ & $<0.0001^{*}$ \\
\hline Maneuvers & $1.7 \pm 0.9$ & $1.6 \pm 0.8$ & $0.824 *$ \\
\hline Three maneuvers or more & $17 \%(9)$ & $11 \%(28)$ & $1.63(0.72,3.69)$ \\
\hline Fracture - clavicle or humerus & $6 \%(3)$ & $3 \%(7)$ & $2.09(0.52,8.37)$ \\
\hline Brachial plexus injury & $6 \%(3)$ & $7 \%(17)$ & $0.82(0.23,2.93)$ \\
\hline
\end{tabular}

Data as mean \pm standard deviation or $\%(\mathrm{n}){ }^{\bullet} \mathrm{BW}=$ birth weight $\mathrm{OR}=$ odds ratio; $\mathrm{CI}=$ confidence intervals

${ }^{\wedge}$ Mann-Whitney test used (failed normality test) *Unpaired t-test

Table 3. Parous parturients with shoulder dystocia and brachial plexus injury (BPI)

\begin{tabular}{|c|c|c|c|}
\hline & $\begin{array}{l}\text { Shoulder dystocia } \\
\text { and BPI } \\
(\mathbf{N}=\mathbf{2 0})\end{array}$ & $\begin{array}{l}\text { Shoulder dystocia } \\
\text { Without BPI } \\
(\mathbf{N}=\mathbf{2 8 4})\end{array}$ & $\begin{array}{c}\mathbf{P} / \\
\text { OR }(95 \% \mathrm{CI})^{\mathrm{x}}\end{array}$ \\
\hline Age & $28.0 \pm 4.7$ & $27.7 \pm 5.6$ & $0.685^{\wedge}$ \\
\hline Gestational age (weeks) & $39.1 \pm 1.2$ & $39.6 \pm 1.1$ & $0.460^{\wedge}$ \\
\hline Prior Largest (BW grams`) & $3496 \pm 486$ & $3538 \pm 483$ & $0.704 *$ \\
\hline Prior shoulder dystocia & 0 & $4 \%(10)$ & $0.64(0.03,11.28)$ \\
\hline Diabetes - gestational or pregestational & $25 \%(5)$ & $6 \%(17)$ & $5.23(1.70,16.12)$ \\
\hline Induced/Augmented & $85 \%(17)$ & $66 \%(188)$ & $2.89(0.82,10.12)$ \\
\hline Epidural & $85 \%(17)$ & $61 \%(172)$ & $3.69(1.06,12.89)$ \\
\hline Spontaneous vaginal delivery & $70 \%(14)$ & $91 \%(259)$ & $0.22(0.08,0.64)$ \\
\hline $\begin{array}{l}\text { Birth weight (g) } \\
\geq 4,000 \mathrm{~g}\end{array}$ & $\begin{array}{c}4110 \pm 514 \\
60 \%(12)\end{array}$ & $\begin{array}{l}3922 \pm 441 \\
42 \%(120)\end{array}$ & $\begin{array}{c}0.113^{\wedge} \\
2.05(0.81,5.17)\end{array}$ \\
\hline $\begin{array}{l}\text { Current BW } \\
\text { Prior Largest BW (g) }\end{array}$ & $614.5 \pm 569.7$ & $384.1 \pm 508.3$ & $0.016^{\wedge}$ \\
\hline$\geq 400 \mathrm{~g}$ & $80 \%(16)$ & $49 \%(139)$ & $4.17(1.36,12.79)$ \\
\hline $\begin{array}{l}\% \text { Difference } \\
\geq 10 \%\end{array}$ & $\begin{array}{l}14.1 \pm 14.9 \% \\
75 \%(15)\end{array}$ & $\begin{array}{l}9.2 \pm 12.9 \% \\
52 \%(146)\end{array}$ & $\begin{array}{c}0.024^{\wedge} \\
2.84(1.00,8.01)\end{array}$ \\
\hline $\begin{array}{l}\text { Maneuvers } \\
\text { McRoberts } \\
\text { Suprapubic } \\
\text { Woods screw } \\
\text { Extraction of arm }\end{array}$ & $\begin{array}{c}2.5 \pm 0.9 \\
100 \%(20) \\
90 \%(18) \\
30 \%(6) \\
25 \%(5)\end{array}$ & $\begin{array}{c}1.6 \pm 0.8 \\
89 \%(252) \\
57 \%(163) \\
13 \%(37) \\
4 \%(10)\end{array}$ & $\begin{array}{c}0.004^{\wedge} \\
5.28(0.31,89.41) \\
6.68(1.52,29.35) \\
2.86(1.03,7.91) \\
9.13(2.77,30.11)\end{array}$ \\
\hline Three maneuvers or more & $40 \%(8)$ & $10 \%(29)$ & $5.86(2.21,15.52)$ \\
\hline Fracture - clavicle or humerus & $35 \%(7)$ & $1 \%(3)$ & $50.44(11.68,217.76)$ \\
\hline
\end{tabular}

Data as mean \pm standard deviation or $\%(\mathrm{n}) \cdot \mathrm{BW}=$ birth weight $\mathrm{OR}=$ odds ratio $\mathrm{CI}=$ confidence intervals

${ }^{\wedge}$ Mann-Whitney test used (failed normality test) *Unpaired t-test

shoulder dystocia and/or maccrosomia does not predict a recurrence of SD the occurrence of BPI.

Secondly, when comparing those where the index pregnancy with shoulder dystocia was the heaviest newborn (Group I) versus those where previous was the heaviest (Group II) the rate of recurrent shoulder dystocia was significantly higher in those in Group I versus Group II ( $2 \%$ vs $10 \%$, OF 0.16 , 95 CI $0.04,0.59)$. Both these findings taken together would indicate that the previous birth weight, whether shoulder dystocia was present or not, cannot be successfully used to predict shoulder dystocia and/or BPI injury in the current or index pregnancy. This is not surprising as even the majority of infants with macrosomia will not develop shoulder dystocia or have BPI [8]. Therefore, it would appear that intrauterine factors such as the attitude of the fetus in the pelvis as well as the conduct of labor may be more important than the actual birth weight in the occurrence of shoulder dystocia and/or BPI $[2,5,9,10]$. Moreover, the literature is replete with data demonstrating the lack of correlation of ultrasound prediction of birth weight antenatally and the actual birth weight [11-13]. Therefore, the significant difference in birth weight between those with shoulder dystocia and BPI $(614 \mathrm{~g})$ versus those with shoulder dystocia and no injury (384 g), while significantly different statistically $(\mathrm{p}=.016)$, is 
not clinically helpful in detecting a 230gm difference because using current ultrasound techniques such discrimination is not possible and may be harmful to the infant by increasing the number of unnecessary cesarean deliveries [14].

Lastly, using stepwise logistic regression there were five significant factors for BPI amongst the parturient. First, shoulder dystocia but not BPI, has been noted to be more common in African American patients [15]. Cheng et al. [15] also found that occiput posterior (OP) position was protective from shoulder dystocia compared to OA position. However, if delivery occurred in the OP position, it was more likely to be associated with BPI whether or not shoulder dystocia was present. In any case, the positive predictive value of these factors are very low, therefore, one cannot use it clinically in an index pregnancy [7]. Likewise, the use of epidural anesthesia has been noted to be a risk factor for shoulder dystocia in other studies [10] and we add confirmatory data of these findings. It was surprising that the use of suprapubic pressure is a risk factor for BPI amongst parous patients, as every treatise, book chapter and article on the subject recommends this maneuver when SD is diagnosed. Whether this is only a statistical association or whether it was related the small numbers of BPI cases in our population is unknown. Accordingly, we feel that the current study does not provide enough evidence to remove suprapubic pressure from our lexicon, as it is a valuable technique for treating women with shoulder dystocia.

Extraction of the posterior arm during a shoulder dystocia is a known risk factor for BPI [16]. What has not been confirmed is whether the BPI occurs in the anterior shoulder after delivery of the posterior arm which is unlikely, or whether the BPI may occur in the posterior arm as risk of the extraction. This seems unlikely, since more of the posterior arm deliveries have been suggested early in the series of maneuvers (to follow the McRoberts/suprapubic pressure) by a large study from the MFM Network rather than resorting to other maneuvers [17]. In any case, this is an acceptable maneuver and should remain, like suprapubic pressure in the treatment algorithm for women with shoulder dystocia in our opinion.

Similarly, the birth weight difference between the largest previous newborn and the index pregnancy is unable to be used prospectively to predict BPI or shoulder dystocia. Obviously, the birth weight of the index pregnancy is not known until after delivery therefore, it cannot be used as a reliable risk factor because the previous pregnancy had no shoulder dystocia. Perhaps in those women a prior shoulder dystocia was present, and in a gestation where the index pregnancy is believed to be $>4500$ gms for a diabetic gravida $(>5000$ gms in euglycemic pregnancies), there might be a place for this factor to be used clinically [4]. However, as previously noted [11-13], antenatal prediction of fetal weight is linked with large errors and it cannot be used to accurately predict those who will clinically develop shoulder dystocia with or without macrosomia.
In conclusion, the previous birth weight in parous women who have a shoulder dystocia, is associated with several risk factors for SD in future gestations. However, we have not been able to show that any of these factors are clinically useful on a prospective basis in a future pregnancy.

\section{References}

1. Gherman RB, Chauhan S, Ouzounian JG, Lerner H, Gonik B, et al. (2006) Shoulder dystocia: the unpreventable obstetric emergency with empiric management guidelines. AM J Obstet Gynecol 195: 657-72. [Crossref]

2. Sandmire H, DeMott RK (2009) Controversies surrounding the causes of brachia plexus injury. J Obstet Gynecol 104: 9-13. [Crossref]

3. Chauhan SP, Rose CH, Gherman RB, Magann EF, Holland MW, et al. (2005) Brachial plexus injury; A 23-year experience from a tertiary center. AM J Obstet Gynecol 192: 1795-802. [Crossref]

4. ACOG Practice Bulletin, Shoulder Dystocia No. 40, November, 2011

5. Sandmire HF, Morrison JC, Racinet C, Hankins G, Pecorari D, et al. (2008) Newborn brachial plexus injuries; the twisting and extension of the fetal head as contributing causes. J Obstet Gynecol 28: 170-172. [Crossref]

6. Koenigsberger MR (1980) Brachial plexus palsy at birth: Intrauterine or due to delivery trauma. Ann Neurol 8: 228.

7. Gilbert WM, Nesbitt TS, Danielsen B (1999) Associated factors in 1611 cases of brachial plexus injury. Obstet Gynecol 93: 536-40. [Crossref]

8. Task Force on Neonatal Brachial Plexus Palsy, The American College of Obstetricians and Gynecologist. Women's Health Care Physicians. Neonatal Brachial Plexus Palsy. 2012-13

9. Jennett RJ, Tarby TJ, Kreinick CJ (1992) Brachial plexus; an old problem revisited. $A M$ J Obstet Gynecol 166: 1673-7. [Crossref]

10. Pollack RN, Buchman AS, Yaff H, Divon MY (2000) Obstetrical bracial palsy; pathogenesis, risk factors, and prevention. Clinical Obstet Gyencol 42: 236-246. [Crossref]

11. Nahum GG, Stanislaw H (2003) Ultrasonographic prediction of term birth weight: how accurate is it? AM J Obstet Gynecol 188: 566-74. [Crossref]

12. Baum JD, Gussman D, Wirth III JC (2002) Clinical and patient estimation of fetal weight vs ultrasound estimation. J Reprod Med 47: 194-198. [Crossref]

13. Sacks DA, Chen W (2000) Estimating fetal weight in the management of macrosomia Obstet Gynecol Survey 55: 229-239. [Crossref]

14. Melamed N, Yogev Y, Miezner I, Mashiach R, Ben-Haroush A (2010) Sonographic prediction of fetal macrosomia the consequences of false diagnosis. J Ultrasound Med 29: 225-30. [Crossref]

15. Cheng YW, Norwitz ER, Caughey AB (2006) The relationship of fetal position and ethnicity with shoulder dystocia and birth injury. AM J Obstet Gynecol 195: 856-62. [Crossref]

16. Hankins GD, Clark SL (1995) Brachial plexus involving the posterior shoulder at spontaneous vaginal delivery. AM J Perinatol 12: 44-5. [Crossref]

17. Hoffman MK, Bailit JL, Branch DW, Burkman RT, Van Veldhusien P, et al. (2011) A comparison of obstetrics maneuvers for the acute management of shoulder dystocia Obstet Gynecol 117; 1272-8. [Crossref]

Copyright: (C2015 Chauhan SP. This is an open-access article distributed under the terms of the Creative Commons Attribution License, which permits unrestricted use, distribution, and reproduction in any medium, provided the original author and source are credited. 